NASA/TM-2002-211551

\title{
Computational Modeling of Vortex Generators for Turbomachinery
}

\author{
R.V. Chima
}

Glenn Research Center, Cleveland, Ohio 
Since its founding, NASA has been dedicated to the advancement of aeronautics and space science. The NASA Scientific and Technical Information (STI) Program Office plays a key part in helping NASA maintain this important role.

The NASA STI Program Office is operated by Langley Research Center, the Lead Center for NASA's scientific and technical information. The NASA STI Program Office provides access to the NASA STI Database, the largest collection of aeronautical and space science STI in the world. The Program Office is also NASA's institutional mechanism for disseminating the results of its research and development activities. These results are published by NASA in the NASA STI Report Series, which includes the following report types:

- $\quad$ TECHNICAL PUBLICATION. Reports of completed research or a major significant phase of research that present the results of NASA programs and include extensive data or theoretical analysis. Includes compilations of significant scientific and technical data and information deemed to be of continuing reference value. NASA's counterpart of peerreviewed formal professional papers but has less stringent limitations on manuscript length and extent of graphic presentations.

- TECHNICAL MEMORANDUM. Scientific and technical findings that are preliminary or of specialized interest, e.g., quick release reports, working papers, and bibliographies that contain minimal annotation. Does not contain extensive analysis.

- CONTRACTOR REPORT. Scientific and technical findings by NASA-sponsored contractors and grantees.
- CONFERENCE PUBLICATION. Collected papers from scientific and technical conferences, symposia, seminars, or other meetings sponsored or cosponsored by NASA.

- SPECIAL PUBLICATION. Scientific, technical, or historical information from NASA programs, projects, and missions, often concerned with subjects having substantial public interest.

- TECHNICAL TRANSLATION. Englishlanguage translations of foreign scientific and technical material pertinent to NASA's mission.

Specialized services that complement the STI Program Office's diverse offerings include creating custom thesauri, building customized data bases, organizing and publishing research results ... even providing videos.

For more information about the NASA STI Program Office, see the following:

- Access the NASA STI Program Home Page at http://www.sti.nasa.gov

- E-mail your question via the Internet to help@sti.nasa.gov

- Fax your question to the NASA Access Help Desk at 301-621-0134

- Telephone the NASA Access Help Desk at 301-621-0390

- Write to:

NASA Access Help Desk

NASA Center for AeroSpace Information 7121 Standard Drive

Hanover, MD 21076 
NASA/TM-2002-211551

\section{Computational Modeling of Vortex Generators for Turbomachinery}

\section{R.V. Chima}

Glenn Research Center, Cleveland, Ohio

Prepared for the

Turbo Expo 2002

cosponsored by the American Society of Mechanical Engineers

and the International Gas Turbine Institute

Amsterdam, The Netherlands, June 3-6, 2002

National Aeronautics and

Space Administration

Glenn Research Center 


\section{Acknowledgments}

This work was supported by the NASA Ultra Efficient Engine project at NASA Glenn Research Center, Kestutis Civinskas, Turbomachinery Project Manager and Carolyn Coles-Hamilton, Core-Compressor Project Manager. Many technical discussions with Dr. Louis Larosiliere and Dr. Gerard Welch are gratefully acknowledged.

Available from

NASA Center for Aerospace Information 7121 Standard Drive

Hanover, MD 21076
National Technical Information Service 5285 Port Royal Road Springfield, VA 22100

Available electronically at http://gltrs.grc.nasa.gov/GLTRS 


\title{
COMPUTATIONAL MODELING OF VORTEX GENERATORS FOR TURBOMACHINERY
}

\author{
R. V. Chima \\ National Aeronautics and Space Administration \\ Glenn Research Center \\ Cleveland, Ohio 44135
}

\section{ABSTRACT}

In this work computational models were developed and used to investigate applications of vortex generators (VGs) to turbomachinery. The work was aimed at increasing the efficiency of compressor components designed for the NASA Ultra Efficient Engine Technology (UEET) program. Initial calculations were used to investigate the physical behavior of VGs. A parametric study of the effects of VG height was done using 3-D calculations of isolated VGs. A body force model was developed to simulate the effects of VGs without requiring complicated grids. The model was calibrated using 2-D calculations of the VG vanes and was validated using the 3-D results. Then three applications of VGs to a compressor rotor and stator were investigated: 1 . The results of the 3-D calculations were used to simulate the use of small casing VGs used to generate rotor preswirl or counterswirl. Computed performance maps were used to evaluate the effects of VGs. 2. The body force model was used to simulate large part-span splitters on the casing ahead of the stator. Computed loss buckets showed the effects of the VGs. 3. The body force model was also used to investigate the use of tiny VGs on the stator suction surface for controlling secondary flows. Near-surface particle traces and exit loss profiles were used to evaluate the effects of the VGs.

\section{NOMENCLATURE}

\begin{tabular}{|c|c|}
\hline$\underset{\hat{B}}{A_{c}, A_{v g}}$ & $\begin{array}{l}\text { cell area, vortex generator planform area } \\
\text { body force vector }\end{array}$ \\
\hline $\mathrm{c}$ & chord \\
\hline$C_{L}, C_{D}$ & lift and drag coefficients \\
\hline$\hat{E}, \hat{G}, \hat{H}$ & inviscid plus viscous fluxes \\
\hline $\mathrm{e}$ & total energy \\
\hline h & vortex generator height \\
\hline$\hat{i}$ & unit vector \\
\hline$J$ & Jacobian of transformation from $(x, y, z)$ to $(\xi, \eta, \varsigma)$ \\
\hline$L, D$ & lift, drag \\
\hline$\vec{F}_{L}, \vec{F}_{D}$ & lift and drag body forces \\
\hline$\hat{K}$ & centrifugal force source term \\
\hline$P, T, V$ & pressure, temperature, velocity \\
\hline$\hat{q}$ & vector of conserved variables \\
\hline$x, y, z$ & Cartesian coordinates \\
\hline$x, \theta, r$ & cylindrical coordinates \\
\hline$u, v, w$ & Cartesian velocity components \\
\hline
\end{tabular}

$\begin{array}{ll}u, v_{\theta}, v_{r} & \text { cylindrical velocity components } \\ \alpha & \text { flow angle } \\ \delta & \text { boundary layer thickness } \\ \xi, \eta, \varsigma & \text { computational coordinates } \\ \rho & \text { density } \\ \sigma & \text { vortex generator stagger angle } \\ \Omega & \text { blade row angular velocity } \\ \omega & \text { loss coefficient }\end{array}$

\section{Subscripts}

$\begin{array}{ll}0 & \text { stagnation state } \\ 1,2 & \text { inlet, exit } \\ L E & \text { leading edge }\end{array}$

\section{Superscripts}

$V^{\prime} \quad$ relative velocity

$\hat{l} \quad$ unit vector in the direction of the lift

$\hat{q} \quad \mathrm{q} / \mathrm{J}$ - divided by the Jacobian

\section{INTRODUCTION}

Vortex generators (VGs) are small, vane-like devices that generate vortices at their tip. They are commonly used to delay separation on aircraft and often used to fix aerodynamic problems that arise during testing. In a typical application the vanes are mounted normal to a wing or fuselage surface in an array that resembles a cascade of turbomachinery blades. The vanes are staggered at an angle that produces an incidence angle with the flow, and the resulting pressure difference across the vanes generates vortices at the tip. The height of the VG is usually slightly higher than the boundary layer, such that the vortices mix high momentum flow from the free stream with low momentum flow near the wall. This increase of momentum near the wall allows the boundary layer to resist adverse pressure gradients. Although VGs can reduce separation, they can produce a measurable increase of drag at cruise (Roskam and Lan, 1997.) The reference by Pearcey (1961) gives an excellent overview of VG theory and applications.

Vortex generators may be grouped into two classes: corotating and counterrotating. Corotating VG vanes are all staggered in the same direction and produce vortices of the same sign. Corotating vortices tend to remain at a constant distance from the surface and persist far downstream. The vortices interact with each other and with the surface 
to turn the flow in the direction of the vane stagger. This characteristic can be exploited to redirect secondary flows on the surface. Corotating vane-type VGs are the most commonly used type of VG and were the only kind considered in the present work.

Counterrotating VG vanes are grouped in pairs with alternating stagger angles and produce vortices of alternating sign. Depending on the blade spacing, the vortex pairs can be made to move towards each other and away from the surface, or away from each other and towards the surface. This characteristic can be used to control the range of effectiveness of the vortices but must be carefully assessed for each application. Counterrotating VGs were not considered in this work.

Many other types of devices have been used as VGs. Vanes, wings, ramps, wedges, leading-edge devices, and wall jets have all been used as VGs. The reference by Liou et al. (1999) gives an interesting comparison of 12 types of VGs and their effects on heat transfer augmentation and skin friction in a square duct.

In the present work CFD models were used to investigate applications of VGs to turbomachinery. The work was aimed at increasing the efficiency of compressor components designed for the NASA Ultra Efficient Engine Technology (UEET) program. One of the program milestones is the design and test of a highly loaded two-stage compressor (Larosiliere, et al. 2001 and Medd, et al. 2001.) The design point pressure ratio is 4.65 at a polytropic efficiency of 92 percent. Two properties of VGs were investigated as means for improving the efficiency or operating range of the first stage rotor and stator. First, their ability to delay separation was investigated as a means for reducing casing boundary layer losses in the rotor. And second, their ability to redirect secondary flows was investigated as a means for reducing incidence losses and spanwise flow migration in the stator.

\section{Previous use of VGs for Turbomachinery and Internal Flows}

A few researchers have attempted to use VGs in turbomachinery. Law, Wennerstrom, and Buzzell (1976) used VGs to energize the casing boundary layer ahead of a transonic fan rotor. They measured an increase in pressure ratio, a 1-2 point increase in efficiency, and some increase in stall margin. They also tried to use small wedge-shaped corotating VGs on the suction side of the rotor blades to reduce shockinduced separation. In this application they measured a minute increase in pressure ratio but lost about one point in efficiency. According to Wennerstrom (1987,) "The results achieved with rotor-mounted vortex generators were less than rewarding."

McCormick (1993) also used low-profile VGs to reduce shockinduced separation on a turbulent flat plate boundary layer. While the extent of the separation was reduced, he found that the mass-averaged total pressure loss increased. Gammerdinger (1995) found similar results in a transonic fan-blade cascade.

At high altitude flight conditions the Reynolds numbers on low pressure (LP) turbine blades is very low and separation is a common problem. Bons, Sondergaard, and Rivir (2000) used both steady and pulsed VG jets to control separation on LP turbine blades in a linear cascade. They completely eliminated separation and reduced wake profile loss by 50 percent.

DeCook, King, and Elrod (1993) used crenulated (notched) trailing edges on a compressor cascade to increase wake mixing. They mea- sured a decrease in total pressure loss of 10-20 percent and a slight decrease in flow turning. Kuethe (1972) attached unusual half-cylinder shaped VGs near the trailing edges of a flat plate and an airfoil to improve wake properties associated with noise. He was able to reduce the wake velocity deficit and suppress vortex shedding. Similar results were found for a transonic fan blade cascade tested by the acoustics branch at NASA Glenn (Lewis) Research Center around 1994 (unpublished.) However, preliminary tests of Kuethe-type VGs affixed to a rotating fan showed little effect on noise generation.

VGs have been used to control secondary flows in inlet ducts. In a collaborative effort between NASA Glenn Research Center and the Defence Research Agency, Anderson and Gibb (1998) used VGs to control vortex liftoff (separation) in an S-shaped inlet duct. Experiments showed large reductions in engine face distortion and unsteadiness. In subsequent work Anderson, et al. (1999) used Design of Experiments techniques with a computational fluid dynamics (CFD) model to optimize VG geometry for an inlet S-duct. Their results showed that very small "MEMS scale" devices, could be used to minimize distortion. Their devices were reported to be on the order of the boundary layer momentum thickness in height, although very long devices appeared to be the most effective. Also at NASA GRC, Wendt and Dudek (1998) combined CFD modeling and experiments to arrange VGs in a subsonic bifurcated diffuser. They were able to reduce engine face distortion by 59 percent with only a 0.3 percent reduction in total pressure recovery. In all of this work CFD modeling was heavily used to optimize VG geometry and placement (Bender, et al. 1999.) The successful use of VGs for controlling secondary flows in inlet ducts motivated many of the present applications to turbomachinery.

\section{Objectives of the Present Work}

In the present work isolated VGs were modeled computationally using direct simulation with the Swift code (Chima, 1996.) A parametric study was performed to determine the effects of VG height on total pressure mixing and flow turning. Next a body force model was developed for Swift that allowed the effects of VGs to be simulated without detailed gridding of the VGs. Then three applications of VGs to turbomachinery were studied:

1 Use of VGs for rotor preswirl. The direct simulation results were used to provide mixed-out inlet conditions to the UEET first stage rotor to simulate the effects of VGs on the casing. Both prewsirl and counterswirl orientations were investigated. Computed performance maps were used to evaluate the effects of the VGs on pressure ratio, efficiency, and stall range.

2 Use of VGs as part-span splitters. The body force model was used to simulate part-span splitters on the casing ahead the UEET first stage stator. Computed loss buckets were used to evaluate the effects of the VGs.

3 Use of blade surface VGs for secondary flow control. The body force model was also used to simulate a spanwise array of VGs along the suction surface of the stator. Many configurations were examined to try to reduce secondary flows. Secondary flow patterns and spanwise loss profiles were used to evaluate the effects of the VGs. 


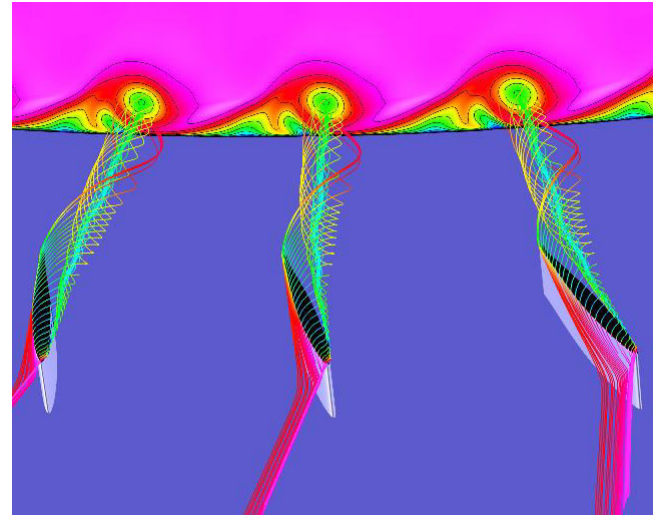

Figure 1.-Computed particle traces and P0 contours, VG height $=1.3 \delta$.

\section{CFD CODES}

\section{RVCQ3D}

The quasi-three-dimensional turbomachinery analysis code RVCQ3D developed by Chima $(1987,1995)$ was used to generate lift and drag coefficients for the VG model. The code solves the thin-layer Navier-Stokes equations in finite-difference form. Radius change and variable stream sheet thickness can be modeled but were not used here. Turbulence effects were modeled using the Baldwin-Lomax model, including the original transition model. The flow equations were solved using an explicit Runge-Kutta scheme. A spatially varying time step and implicit residual smoothing were used to accelerate convergence. Solutions were run on a C-shaped grid with $191 \times 45$ points. Typical solution times were about one minute per case on an SGI Octane workstation.

\section{Swift}

All three-dimensional solutions were run using the Swift multiblock turbomachinery analysis code developed by Chima (1996.) Swift solves the three-dimensional Navier-Stokes equations using algorithms similar to RVCQ3D. Multiblock capabilities allow the tip clearance region over a blade to be computed directly, so isolated VGs were modeled as stators with a very large clearance. The Baldwin-Lomax turbulence model was used for all rotor cases based on considerable past experience. The $\mathrm{k}-\omega$ model was used for all stator/VG applications and isolated VG cases, where resolution of discrete vortices was expected to challenge the algebraic model. Most 3-D computations were run on the Cray C90 at NASA Ames Research Center (von neumann) and took about two hours per case. Swift autotasks well so that most cases took less than 30 minutes wall clock time.

\section{DIRECT CALCULATION OF ISOLATED VGS}

Isolated VG vanes were analyzed using Swift to examine the effect that the VGs had on the flowfield and to investigate the effects of VG height on their performance. Although VGs are often made from flat plates, it was felt that more sophisticated vane shapes might be used in a turbomachinery application. Hence, a NACA 64-006 profile with a rounded trailing edge was used. The vanes were sized to fit on the casing in front of the UEET compressor rotor in an arrangement like that used by Law, et al. (1976.) Using five vanes per rotor passage plus one

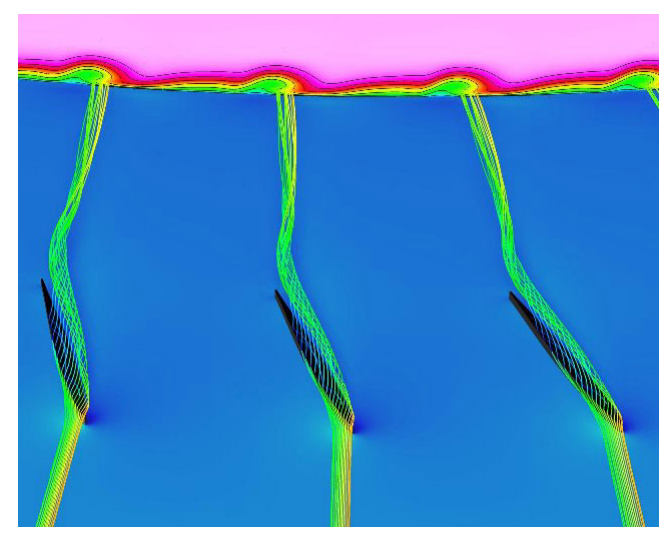

\section{Figure 2.-Computed particle traces and P0 contours, VG height $=\delta / 4$.}

to reduce resonances gave 131 vanes. Common practice for VGs is to use a solidity of one and a stagger angle of 20 degrees. This gave an aerodynamic chord of $12.7 \mathrm{~mm}(0.5 \mathrm{in}$.)

Computational grids were generated for the vanes. The grids had two blocks. A C-shaped block was used around the vanes with 191 points in the C-direction and 45 points from vane to mid-passage. Sixty three points were used spanwise, with $15-31$ points along the vane depending on height. An O-shaped block filled the hole above the tip of the vanes. The total grid size was about $554 \mathrm{~K}$ points. The grid extended 4.4 VG heights above the VGs and 2 chords downstream.

Boundary conditions for Swift were specified as follows: At the inlet boundary total temperature and flow angles were specified as constant, and a total pressure profile was specified to match an equilibrium turbulent wall-wake velocity profile with a boundary layer thickness $\delta=1.9 \mathrm{~mm}(0.075 \mathrm{in}$.) At the exit boundary the static pressure was set to give a free stream Mach number $M=0.53$

Four vane heights were analyzed, $h=1.3 \delta, \delta / 2, \delta / 4$, and $\delta / 8$, where $\delta=1.9 \mathrm{~mm}(0.1 \mathrm{in}$.). The largest vane height, $h=1.3$ was five times the rotor tip clearance. The smallest vane height, $h=\delta / 8$ was on the order of the boundary layer displacement thickness. Since the vanes were immersed in a turbulent boundary layer, the flow over them was modeled as fully turbulent using the $\mathrm{k}-\omega$ model.

Figure 1 shows the computed solution for $h=1.3 \delta$. Particle traces colored by total pressure leaving the tip of the vane show the structure and path of the tip vortices. The core of the vortices has low total pressure but the outer portion of the vortices clearly transports high total pressure flow from above the vanes to the wall. Total pressure contours on the exit plane show how boundary layer height is reduced on the pressure side of the passage and increased on the suction side. Figure 2 shows similar results for $h=\delta / 4$. Here the oncoming boundary layer flow has much lower momentum and the vortex strength is greatly reduced.

The flow at the exit planes was energy-averaged circumferentially and the resulting spanwise profiles of total pressure and flow angle are shown in figs. 3 and 4 respectively. The unmodified boundary layer profile is shown for reference. The total pressure profiles in fig. 3 show that the two largest VGs transport core flow to the wall. The profiles near the wall are similar for $h=1.3 \delta$ and $h=\delta / 2$, but the VGs with $h=\delta / 2$ have less impact on the core flow. The two smallest VGs have little effect on the total pressure profiles. 


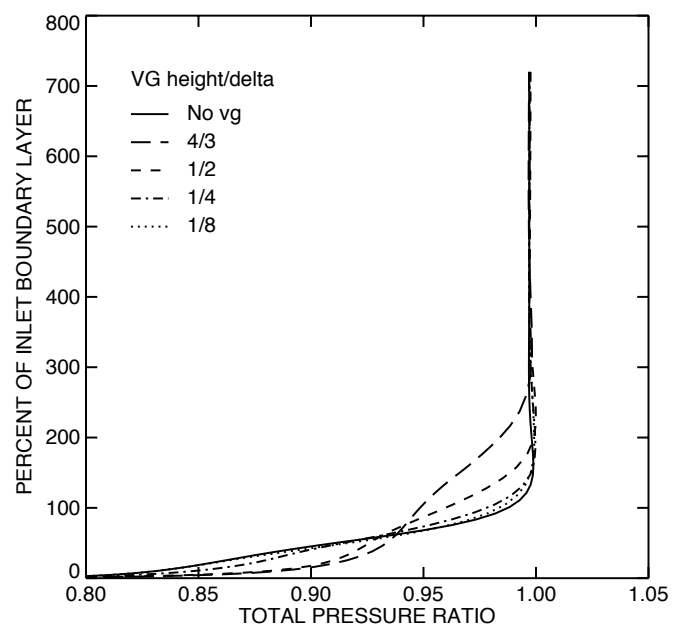

Figure 3.-Spanwise P0 profiles two chords downstream of VGs.

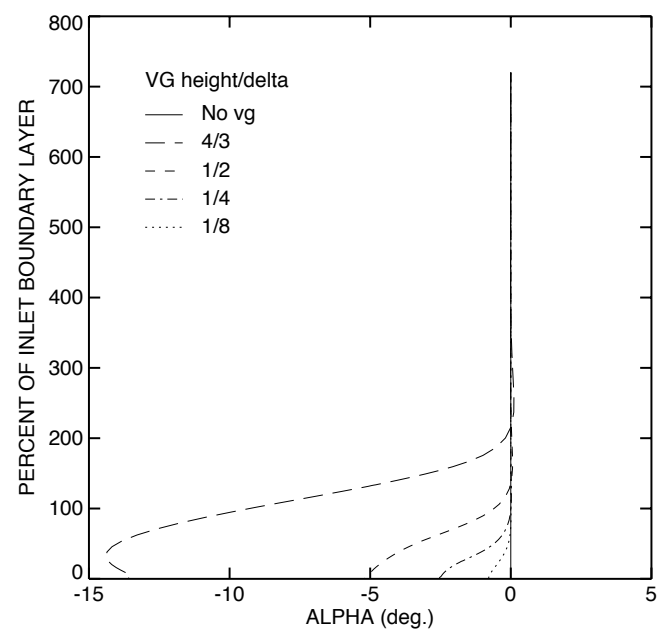

Figure 4.-Spanwise turning angle profiles two chords downstream of VGs.

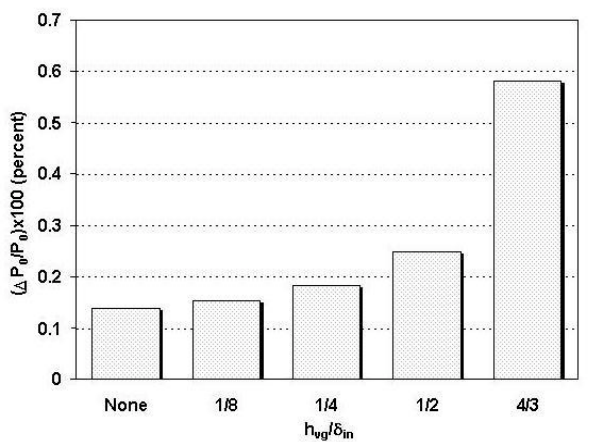

Figure 5.-Effect of VG height on PO loss.

The turning angle profiles in fig. 4 show that the turning decreases quickly with vane height. Overall total pressure losses calculated between the grid inlet and exit are shown in fig. 5. The two smallest VGs show little additional loss over the unmodified boundary layer. VGs with $h=\delta / 2$ increase the baseline loss about 60 percent, but

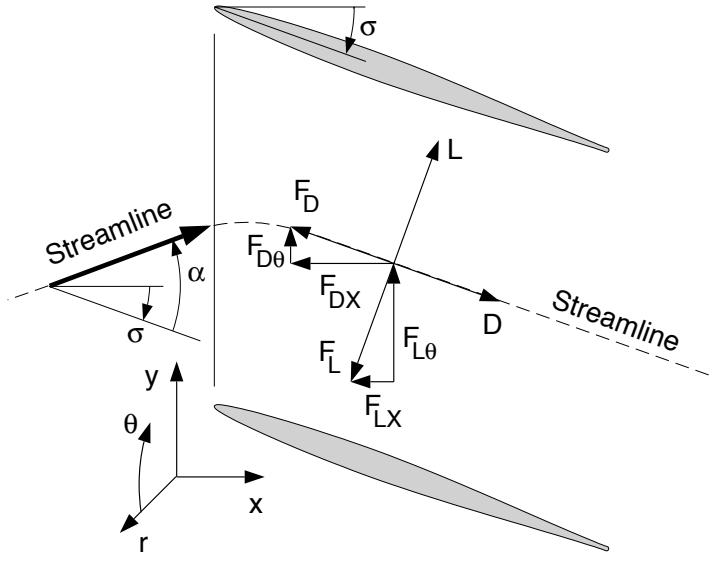

Figure 6.-Body force nomenclature for VG model.

VGs with $h=1.3 \delta$ nearly quadruple the loss. The results of this parametric study suggest that $h=\delta / 2$ is about optimal for mixing the flow with minimum loss, but that tall VGs must be used if the intent is to turn the flow.

\section{VG MODEL}

\section{Formulation}

A computational model of vortex generators was developed and implemented in the Swift code. The model uses body force terms to produce the effects of VGs on the flow without the difficulties of gridding and solving the flow around the VGs directly. The model was based on the one developed by Bender, et al. (1999.) Bender's model used a lift force normal to the flow to turn the flow. The lift force was proportional to the difference between the desired flow angle and the actual flow angle. The constant of proportionality was shown to have an "asymptotic mode" in which the strength of the induced vortex was independent of the value of the constant. No drag force was included so that the model produced no losses.

The present model includes a lift body force that turns the flow and a drag body force that produces losses. The body forces were assumed to be proportional to standard lift and drag coefficients that are functions of the incidence angle. The lift and drag coefficients were calibrated using two-dimensional RVCQ3D calculations of a cascade of VGs. The model described below applies to VGs on the hub or casing of a turbomachine. Similar equations may be derived for VGs on the blade surfaces with a simple change of variables.

Figure 6 shows a cascade of VGs stacked along a radial line and set at a stagger angle $\sigma$ with respect to the $x$-axis. The flow direction is at an incidence angle $\alpha$ with respect to the stagger angle. The aerodynamic forces on the blades are a lift force $\vec{L}$ normal to the flow direction and a drag force $\vec{D}$ in the flow direction. The body forces on the flow $\overrightarrow{F_{L}}$ and $\overrightarrow{F_{D}}$ are equal and opposite to $\vec{L}$ and $\vec{D}$.

For the Swift code the Navier-Stokes equations are written in Cartesian coordinate system rotating around the $x$-axis with angular velocity $\Omega$. The equations are transformed to a general body-fitted coordinate system using standard finite-difference techniques (Chima, 1992) and may be written as: 


$$
\partial_{t} \hat{q}+\partial_{\varepsilon} \hat{E}+\partial_{\eta} \hat{G}+\partial_{\varsigma} \hat{H}=\hat{K}+\hat{B}
$$

where $\hat{q}=(\rho, \rho u, \rho v, \rho w, e) / J$ is the vector of conserved variables, $\hat{E}, \hat{G}$, and $\hat{H}$ are vectors containing the inviscid and viscous fluxes, and $\hat{K}$ contains centrifugal force terms for the $y$ - and $z$-momentum equations. Here the caret notation denotes division by the Jacobian of the coordinate system transformation $J$. The body force term $\hat{B}$ is given by

$$
\hat{B}=\frac{1}{J}\left[\begin{array}{l}
0 \\
\left(\overrightarrow{F_{L}}+\overrightarrow{F_{D}}\right)_{x} \\
\left(\overrightarrow{F_{L}}+\overrightarrow{F_{D}}\right)_{y} \\
\left(\overrightarrow{F_{L}}+\overrightarrow{F_{D}}\right)_{z} \\
r \Omega\left(\overrightarrow{F_{L}}+\overrightarrow{F_{D}}\right)_{\theta}
\end{array}\right]
$$

where $F_{\theta}=\left(F_{y} z-F_{z} y\right) / r$ and

$$
\begin{gathered}
\overrightarrow{F_{L}}=\frac{1}{2} \rho\left|V^{\prime}\right|^{2} C_{L} A_{c} \frac{A_{v g}}{\sum A_{c}} \hat{l} \\
\overrightarrow{F_{D}}=\frac{1}{2} \rho\left|V^{\prime}\right|^{2} C_{D} A_{c} \frac{A_{v g}}{\sum A_{c}} \hat{d}
\end{gathered}
$$

Here

$$
\frac{1}{2} \rho\left|V^{\prime}\right|^{2}=\frac{1}{2} \rho\left[u^{2}+v^{\prime 2}+w^{\prime 2}\right]
$$

is the dynamic head in the relative frame of reference and $v^{\prime}=v-\Omega y, w^{\prime}=w+\Omega z$ are relative velocity components. $C_{L}$ and $C_{D}$ are lift and drag coefficients, $A_{c}$ and $A_{v g}$ are areas, and $\hat{l}$ and $\hat{d}$ are unit direction vectors described below.

The energy equation includes a term for the work done on the fluid by rotating VGs, for example by VGs mounted on a rotating hub. It could also include a term like $\overrightarrow{V^{\prime}} \cdot \overrightarrow{F_{D}}$, but the model assumes that this term exactly cancels the entropy rise term due to the drag forces. In this way the drag model does not change the total enthalpy of the flow (see Marble, 1964.)

The VG model is applied on grid surfaces that approximate the VG planform. For VGs on the hub or casing, the model is applied on a $(\varepsilon, \varsigma)$ surface, and the $\eta$-coordinate is approximately normal to that surface. Then $A_{c}$ is the cell area in the direction of the planform, and is given by:

$$
A_{c}=\frac{\eta_{\theta}}{r J \cos \sigma}
$$

where $\eta_{\theta}=\left(\eta_{y} y_{\theta}+\eta_{z} z_{\theta}\right)=\left(-\eta_{y} z+\eta_{z} y\right)$.

$A_{v g} / \sum A_{c}$ is the ratio of the planform area of the real VGs to the total cell area on which the model is applied. The model is usually applied on grid surfaces with the same total area as the real VG planform. To generate discrete vortices the model is applied over two neighboring surfaces, and $A_{v g} / \sum A_{c}=1 / 2$. Two surfaces are used to reduce discontinuities in the finite-difference solution. The model may also be applied over $n$ consecutive surfaces to generate the overall turning and loss produced by the VGs without resolving discrete vortices. In this case $A_{v g} / \sum A_{c}=1 / n$.

The lift force is assumed to be normal to both the local relative flow direction and the spanwise (radial) direction. In this way it can turn the flow without producing losses. Using carets to denote unit vectors, the unit vector in the relative flow direction is $\hat{V}^{\prime}=\left(u i_{x}+v_{\theta}^{\prime} i_{\theta}+v_{r} i_{r}\right) /\left|V^{\prime}\right|$. The unit spanwise vector is $\hat{s}=0 i_{x}+0 i_{\theta}+\hat{s}_{r} i_{r}$, where $\hat{s}_{r}=1$ for VGs on the hub or $\hat{s}_{r}=-1$ for VGs on the casing. The unit vector in the direction of the lift is given by:

$$
\begin{aligned}
\hat{l} & =\hat{V}^{\prime} \times \hat{s} \\
& =\frac{\hat{s}_{r}}{\left|V^{\prime}\right|}\left(v_{\theta}{ }^{\prime} i_{x}-u i_{\theta}\right)
\end{aligned}
$$

where $v_{\theta}^{\prime}=\left(v^{\prime} z-w^{\prime} y\right) / r$ and $i_{\theta}=\left(i_{y} z-i_{z} y\right) / r$.

The drag force is assumed to be parallel but opposed to the relative flow direction so that it can produce losses without turning the flow. The unit vector in the direction of the drag is given by:

$$
\hat{d}=-\left(u i_{x}+v^{\prime} i_{y}+w^{\prime} i_{z}\right) /\left|V^{\prime}\right|
$$

\section{Calibration}

The lift and drag coefficients $C_{L}$ and $C_{D}$ were calculated for a 2-D cascade of VG blades using the RVCQ3D code (Chima, 1996.) The blade shapes and flow conditions were the same as those used for the 3D simulations described earlier, i.e., solidity $=1$, stagger angle $=20$ degrees, and $M=0.53$. Several incidence angles were run. The pressure forces and shear forces in the $x$ - and $y$-directions were integrated around the blades and output, along with the inlet dynamic head and inlet and exit flow angles.

An average flow angle $\bar{\alpha}$ was calculated and the forces were resolved into components tangent and normal to the average flow direction, similar to the procedure given by Dixon, (1975.)

$$
\begin{gathered}
\bar{\alpha}=\operatorname{atan}\left[\frac{1}{2}\left(\tan \alpha_{1}+\tan \alpha_{2}\right)\right] \\
L=-f_{x} \sin \bar{\alpha}+f_{y} \cos \bar{\alpha} \\
D=f_{x} \cos \bar{\alpha}+f_{y} \sin \bar{\alpha} \\
C_{L}=\frac{L}{\frac{1}{2} \rho\left|V^{\prime}\right|^{2} c h} \\
C_{D}=\frac{D}{\frac{1}{2} \rho\left|V^{\prime}\right|^{2} c h}
\end{gathered}
$$

where $c$ is the chord and the height $h=1$. The results are plotted in fig. 7 as a function of incidence angle $\alpha$, which can be approximated as: 


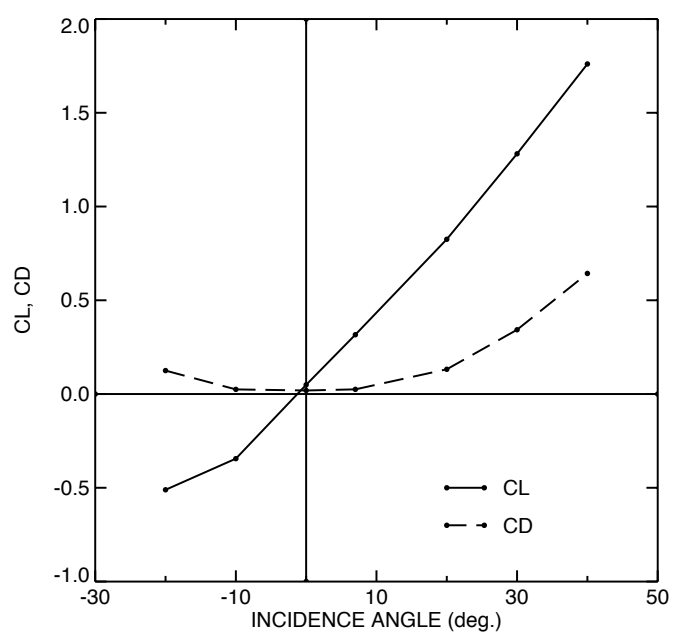

Figure 7.-Calculated lift and drag curves for VG cascade, $\sigma=20$ deg.

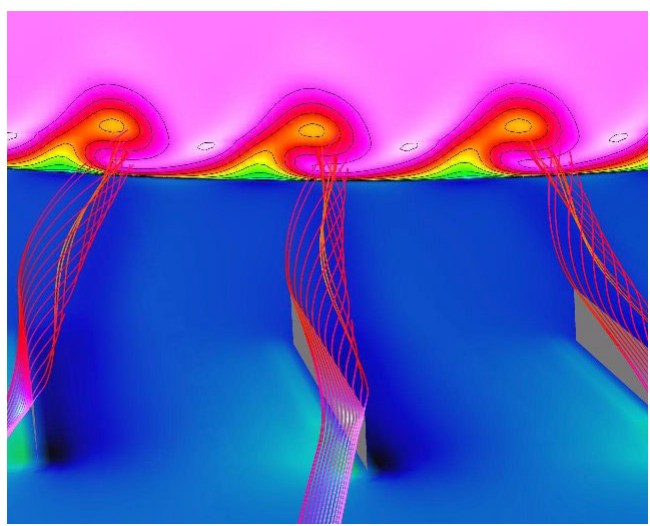

Figure 8.-Particle traces and P0 contours computed using VG model, VG height $=1.3 \delta$.

$$
\begin{gathered}
\alpha \approx \sin \alpha=\hat{V}_{L E}^{\prime} \cdot \hat{n} \\
\hat{n}=-\sin \sigma i_{x}+\cos \sigma i_{\theta}+0 i_{r} \\
\alpha \approx\left(-u_{L E} \sin \sigma+v_{L E}^{\prime} \cos \sigma\right) /\left|V^{\prime}\right|
\end{gathered}
$$

$C_{L}$ is linear for $-10^{\circ} \leq \bar{\alpha} \leq 40^{\circ}$, and $C_{D}$ is linear with $C_{L}^{2}$. $C_{L}$ and $C_{D}$ were curve fit using:

$$
\begin{gathered}
C_{L} \approx 2.356 \bar{\alpha} \\
C_{D} \approx 0.019+0.1637 C_{L}^{2}
\end{gathered}
$$

These coefficients are only valid for VGs with a solidity of 1 and a stagger angle of 20 degrees in turbulent flow. They should be nearly independent of Mach number as long as the flow remains subsonic.

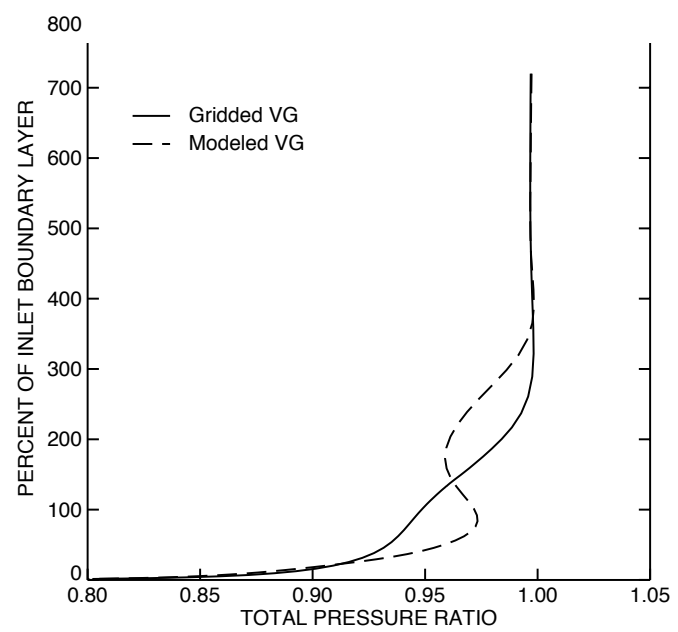

Figure 9.-Comparison of modeled and resolved P0 profiles.

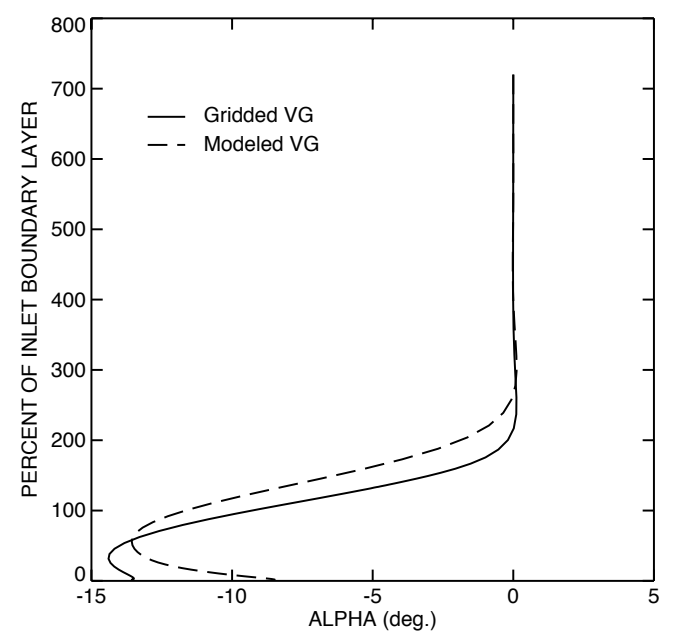

Figure 10.-Comparison of modeled and resolved turning angle profiles.

\section{Validation}

The VG model was used to recompute the solution for the isolated VGs with $h=1.3 \delta$ shown in fig. 1 . For these calculations the $191 \times 45$ point C-grid was replaced with a uniform $97 \times 27$ point $\mathrm{H}$ grid, but spanwise clustering was unchanged to maintain the boundary layer resolution. The body force model was applied on two grid planes near the center of the grid.

Particle traces and exit total pressure contours computed with the VG model are shown in fig. 8 and may be compared with the direct calculations shown in fig. 1, which has the same contour levels. The modeled vortex lacks the detailed structure of the direct solution and does not pick up the low pressure core of the computed vortex, but the effects on the exit total pressure contours are quite similar. Figure 9 compares the spanwise total pressure profiles from the model with that from the direct calculations. The model overpredicts the mixing but does match the wall shear and overall losses closely. Figure 10 shows that the model matches the turning almost exactly. 


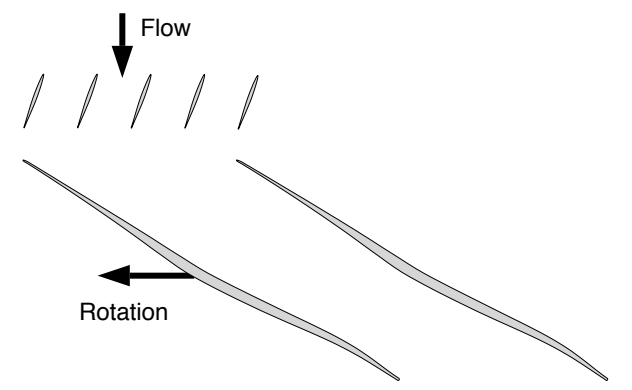

Figure 11.-Casing VGs ahead of UEET rotor 1 tip section.
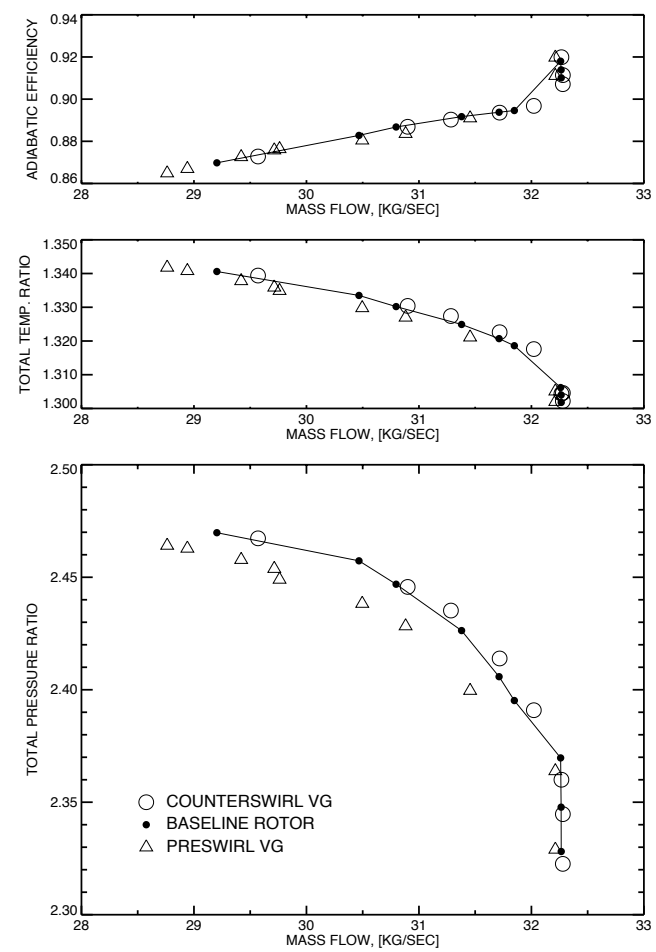

Figure 12.-Effect of pre and counterswirl VGs on UEET rotor performance.

\section{APPLICATIONS TO TURBOMACHINERY}

\section{Use of VGs for rotor preswirl}

Law, et al. (1976) used VGs to energize the casing boundary layer ahead of a transonic fan rotor, reasoning that a healthier boundary layer would delay stall and possibly increase efficiency. They used corotating VGs staggered in the same direction as the rotor, based on an argument that gyroscopic forces induced by blade-to-blade pressure forces would keep the vortices close to the casing. They sized their VGs based on intuition and on recommendations in Pearcey (1961,) using a height of 2.4 times the rotor clearance, a stagger angle of 20 degrees, and about 4.8 VGs per rotor passage. They measured an increase in pressure ratio, a 1-2 point increase in efficiency, and some increase in stall margin.

A similar application was considered here by modeling an array of VGs on the casing ahead of the UEET rotor 1, shown at the tip in fig. 11. The VGs were modeled by using the results of the direct calculations of isolated VGs as mixed-out inlet conditions to the UEET first stage rotor. The VG height was taken as $h=1.3 \delta=2.54 \mathrm{~mm}(0.1 \mathrm{in})$. This height was five times the tip clearance or about two percent of the rotor span.

For the rotor calculations, spanwise profiles of $P_{0}, T_{0}$, and $v_{\theta}$ were specified at the inlet boundary. Over most of the span these quantities were obtained from a previous analysis of an inlet guide vane. Over the last three percent of the span these quantities were obtained from the isolated VG calculations. By changing the sign on $v_{\theta}$ both counterswirl and preswirl VGs could be simulated. Counterswirl VGs were staggered like the rotor blades (but much less) and turned the flow against the rotor rotation. Preswirl VGs were staggered opposite to the rotor blades and turned the flow in the direction of rotor rotation.

The inlet axial and radial velocity components of the profile were determined as part of the solution. The casing static pressure was prescribed at the rotor exit and radial equilibrium was used to determine the nominal spanwise pressure distribution. A characteristic boundary condition allowed the exit static pressure to vary tangentially about the nominal values.

A C-type grid was used around the rotor with 209 points around the blade, 46 points from blade to mid-passage, and 61 points spanwise. An O-type grid was used in the tip clearance region, with 9 points between the blade tip and the casing. The total grid size was 607,778 points. Operating maps were calculated by changing the exit casing static pressure. Solutions near maximum flow converged to constant mass flow and pressure ratio in 2-3000 iterations. Stall points were determined by restarting from a solution at a higher flow and increasing the exit pressure slightly until the solutions either diverged or the mass flow fell well below the expected stall point. The stall point for the case with counterswirl VGs was run 19,000 iterations to assure convergence. The numerical stall points are known to within $0.23 \mathrm{~kg} / \mathrm{sec}(0.5 \mathrm{lbm} / \mathrm{sec}$, but it is not known how well the numerical stall points corresponds to the physical stall points.

Calculated performance maps of pressure ratio, temperature ratio, and adiabatic efficiency are shown in fig. 12. The solid line represents the baseline rotor without VGs. Counterswirl VGs (O's) turn the inlet flow in a direction opposite to the blade rotation, thereby loading up the tip sections and increasing the pressure and temperature ratios accordingly. This is consistent with the experiments with counterswirl VGs described by Law, et al. (1976.) However, the experiments showed an increase in mass flow range, while the calculations show a 12 percent decrease in flow range. Preswirl VGs ( $\Delta$ 's) unloaded the tip and decreased the pressure and temperature ratios, but increased the flow range by nearly 15 percent. Both of the computed VG configurations showed a negligible decrease in adiabatic efficiency.

The present results suggest that small preswirl VGs could have a large impact on stall range. However; there are several limitations to these calculations. First, prediction of stall points is notoriously unreliable. Second, the present results are steady, but the actual rotor would see unsteady loads due to the VGs that could be detrimental to performance. Finally, in the present calculations the beneficial effects of the VGs on the casing boundary layer are applied at the rotor inlet boundary. In reality discrete vortices would convect into the moving rotor and could influence the casing boundary layer well downstream. Thus it is clear that either experiments or detailed unsteady calculations would be required to confirm these results. 

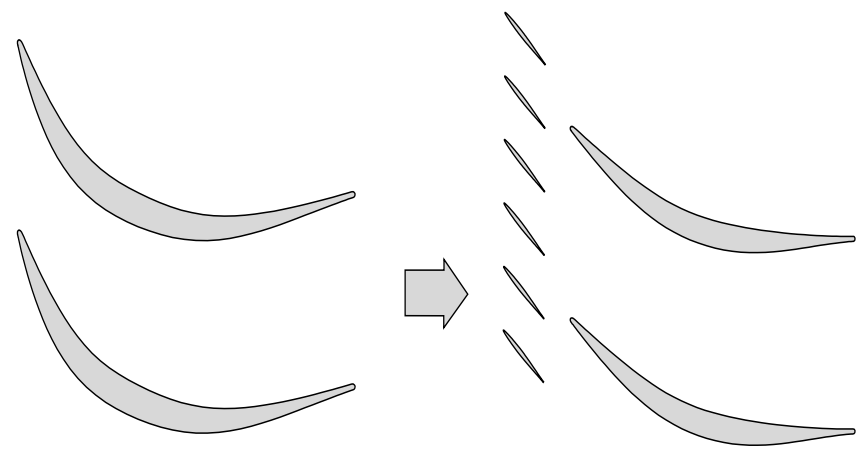

Figure 13.-Left: tip section of 3-D UEET stator 1. Right: VGs + flank-milled stator

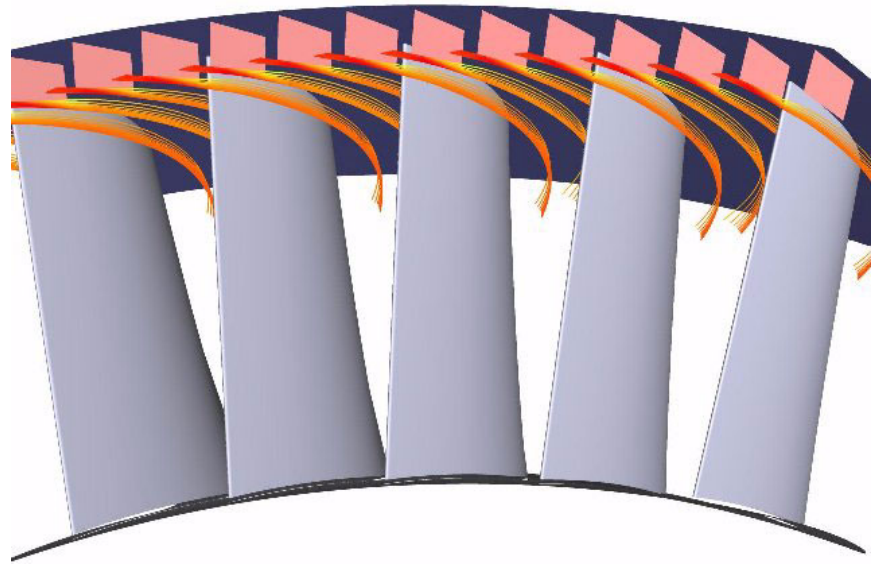

Figure 14.-Particle traces from part-span splitter VGs.

\section{Use of VGs as part-span splitters}

In a second application, VGs were used as part span splitters to control incidence effects on the casing ahead of a redesigned UEET stator. These stators are highly three-dimensional, with bow and sweep. The tip sections (fig. 13 left) are highly cambered to deal with the overturned flow leaving the rotor. In this application it was proposed that the 3-D stator blade could be replaced with a straight (or flank-milled) blade (fig. 13 right) that would be easier to build. The straight blade would also have less surface area than the 3-D blade, and hopefully lower skin-friction losses as well. An array of VGs was to be used on the casing to guide the overturned flow from the rotor into the stator passages (fig. 13 right.)

A straight stator was designed with a constant camber line and a linear thickness variation along its span. It had the same chord as the 3-D blade at the hub and the same turning as the 3-D blade at mid span. Three VGs were equally spaced across each stator passage, giving a spacing of $10.2 \mathrm{~mm}(0.4 \mathrm{in}$.) The solidity was set to one. The VGs were staggered at the stator inlet angle of 43 degrees, giving an axial chord of $7.5 \mathrm{~mm}$ (0.29 in.) The VG height was set to 10 percent of the stator span ( $7.6 \mathrm{~mm}$ or $0.3 \mathrm{in}$,) corresponding to the region of highest rotor overturning.

A computational grid was generated for the stator with $173 \times 46 \times 51=405,858$ points. The stators were cantilevered and

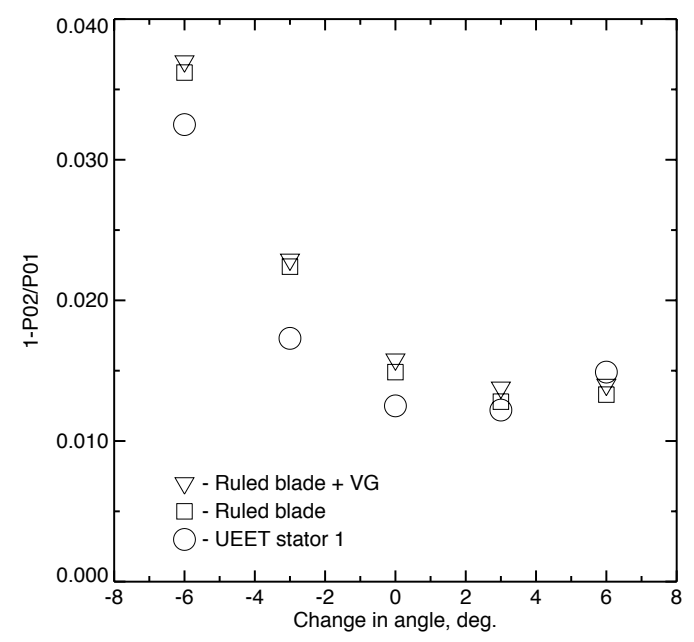

Figure 15.-Effect of part-span splitter VGs on UEET stator losses.

the hub clearance effects were modeled using a simple periodic boundary condition applied over seven points. This clearance model is exact for infinitely thin blades and works quite well for most compressor geometries (see Chima, 1996 for details.)

The VGs were computed using the body force model applied on a separate H-grid just ahead of the stator. The lift and drag coefficients given in equation (10) were calculated for VGs staggered at 20 degrees. For the present stagger angle of 43 degrees the lift and drag coefficients were recalculated as:

$$
\begin{gathered}
C_{L} \approx 3.546 \bar{\alpha} \\
C_{D} \approx 0.0148+0.0607 C_{L}^{2}
\end{gathered}
$$

Figure 14 shows the arrangement of the VGs ahead of the stator blades. Computed particle traces show the tip vortices. In this application the VGs were mainly used to turn the flow, and the vortices were not expected to affect the casing boundary layer appreciably.

The rotor exit $P_{0}, T_{0}$, and $v_{\theta}$ profiles were specified as inlet profiles to the stator. To simulate off-design operation, the rotor exit velocity was rotated tangentially \pm 6 degrees and new $v_{\theta}$ profiles were generated. These profiles were used to generate the loss buckets shown in fig. 15. The baseline 3-D stator (O's) has low losses for incidence angles between -2 and +6 degrees. Losses increase considerably for angles less than -2 degrees. The straight blade alone ( $\square$ 's ) has only slightly higher losses than the 3-D blade. The straight blade with VGs $\left(\nabla^{\prime} s\right)$ is slightly worse that the straight blade alone, except at the highest incidence.

Examination of the solutions for the 3-D baseline blades revealed that the high losses at negative incidence were due to high Mach numbers near the hub, and that the blades were fairly insensitive to incidence effects at the tip. Since the straight blade matched the 3-D blade at the hub, its performance was similar to the 3-D blade. In this application the part-span splitter VGs had little effect except to add their own losses to the flow. In other applications part-span splitter VGs might still prove to be a viable concept. 


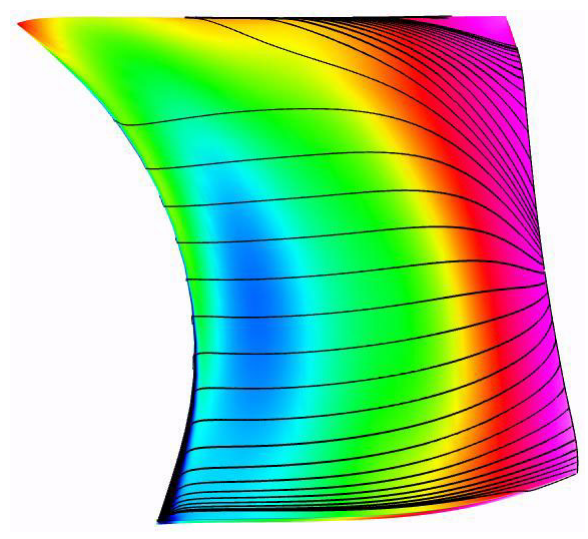

Figure 16.-Pressure contours and secondary flows on the suction side of UEET stator 1 .

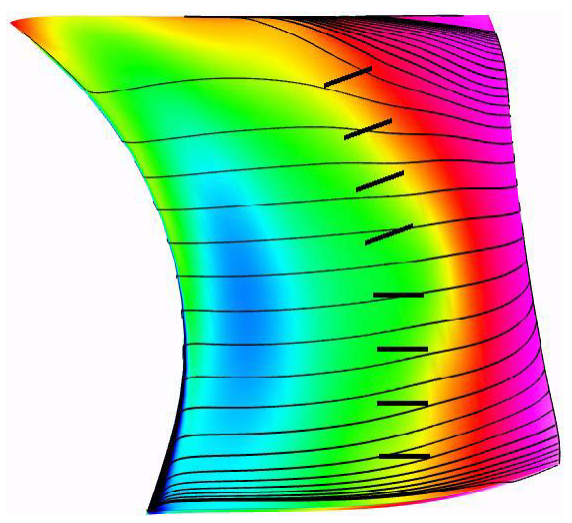

Figure 17. - Reduction in secondary flows using suction surface VGs.

\section{Use OF blade surface VGs for secondary flow control}

Anderson, et al. $(1998,1999)$ used VGs to control secondary flows in S-shaped inlet ducts. A similar application was considered here by using VGs to control secondary flows on the suction side of the UEET stator. CFD solutions of these stators show strong secondary flows on the suction side. Figure 16 shows suction side pressure contours and near-surface flow patterns for a case at design incidence. Secondary flows migrate up from the hub and down from the casing, merging near mid span. At other incidence angles the secondary flows merge into small separation bubbles. In this application spanwise arrays of VGs were used to redirect the secondary flows. It was hoped that this would reduce losses by shortening the streamlines and reducing the size of separation bubbles.

VGs were arranged spanwise on the suction side of the stators in various configurations like the one shown in fig. 16. The VGs had a chord of about $6.35 \mathrm{~mm}(0.25 \mathrm{in})$ and a solidity of one to give $8-10 \mathrm{VGs}$ along the span. The VGs were staggered \pm 20 degrees. Suction surface boundary layer heights were estimated from earlier solutions, and VG heights were chosen with $h=\delta / 2=0.71 \mathrm{~mm}$ ( $0.028 \mathrm{in}$.) The body force model was applied over a region of the grid to simulate the overall effects of the VGs without resolving discrete vortices. The grid size was the same as in the previous section.

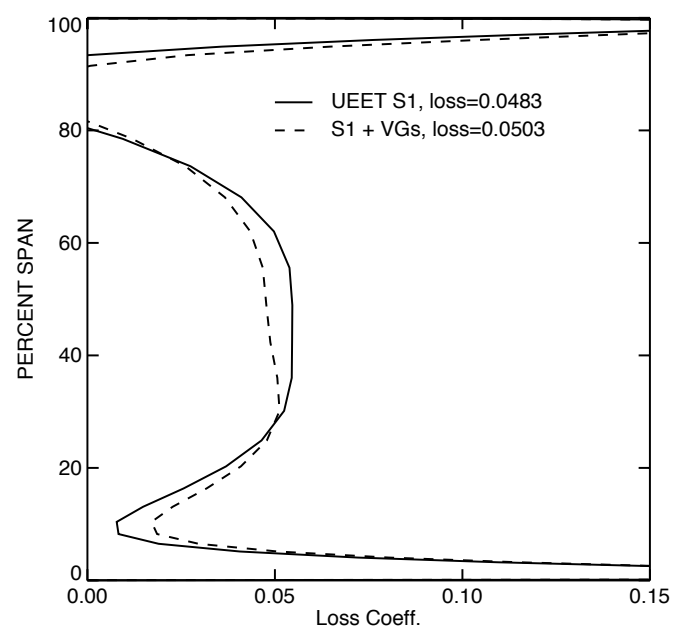

Figure 18.-Effect of suction surface VGs on stator spanwise los profile.

Several configurations of VGs were considered. The best results are shown in fig. 17. Here eight VGs were arranged spanwise between approximately 60 and 70 percent chord. The upper four were staggered upwards and the lower four were unstaggered. The resulting surface pressures were modified slightly (compare figs. 16 and 17) and the secondary flows were successfully reduced, as shown by the nearly straight surface streamlines.

The solutions were energy-averaged circumferentially and the spanwise profiles of loss coefficient $\omega=\left(P_{01}-P_{02}\right) /\left(P_{01}-P_{1}\right)$ are compared in fig. 18 . The apparently negative loss near the tip results from spanwise redistribution of the flow. Inside the stator passage high loss flow from the tip of rotor 1 exchanges places with better flow from lower along the span, such that the losses appear negative near the tip. With VGs the core loss decreased about a point over much of the midspan region, but the loss increased near the endwalls. The net loss increased by 0.2 points with VGs.

At -6 degrees of incidence the secondary flows were stronger and harder to control with VGs. Many VG configurations were examined but the results always showed the same trend: it was possible to reduce the secondary flows with VGs but the loss always showed up somewhere else, and the net loss was always slightly worse with VGs.

\section{CONCLUSIONS}

In this work CFD models were used to investigate applications of vortex generators (VGs) to turbomachinery. The work was aimed at increasing the efficiency of compressor components designed for the NASA Ultra Efficient Engine Technology (UEET) program. Initial calculations were used to understand the physical behavior of VGs and to develop a simple CFD model of VGs. Then three applications of VGs to the first stage of the UEET compressor were investigated. The following conclusions were made:

1 A parametric CFD study of corotating VGs suggested that the optimal VG height for mixing the flow with minimum loss is about half the boundary layer thickness, but that taller VGs should be used to turn the flow.

2 A body force model was developed that allows the effects of VGs to be added to turbomachinery calculations without gridding the VGs directly. The model was calibrated using lift and drag coefficients 
calculated with a 2-D CFD code (RVCQ3D,) and validated against 3-D calculations of fully gridded VGs. The VG model reproduced the wall shear, overall total pressure loss, and turning of the fullygridded calculations correctly, although mixing was overpredicted.

3 The results of the parametric study were used to simulate VGs on the casing ahead of the UEET first stage compressor rotor. The computed VG exit profiles were averaged circumferentially and used as mixed-out inlet conditions near the tip of the rotor. Performance characteristics were calculated for the baseline rotor alone and with counterswirl and preswirl VGs. The counterswirl orientation gave a slight increase in total pressure rise but reduced the stall margin. The preswirl orientation reduced the pressure rise slightly, but increased the stall margin. Neither orientation changed the efficiency significantly. The results suggest that small preswirl VGs (about two percent span high) could be used to increase the stall margin of compressors with little impact on performance. However, detailed unsteady calculations or experiments would be needed to confirm these results.

4 The body force model was used to simulate part-span splitters on the casing ahead of a stator. Here the bowed and swept UEET first stage stator was replaced with a straight blade plus an array of tall VGs (10 percent span high) on the casing to deal with overturned flow from the upstream rotor. Loss buckets were calculated for the baseline blade and the straight blade with and without VGs. The results showed that this stator was relatively insensitive to incidence at the tip, so that VGs did not improve the performance of the straight blade. Part-span splitter VGs might still prove to be useful in other applications.

5 The body force model was also used to control secondary flows on the suction side of the UEET stator. Here an array of very small VGs (less than $1 \mathrm{~mm}$ high) were used to turn spanwise secondary flows back towards the endwalls. The results showed that secondary flows could be nearly eliminated at low incidence and reduced at high incidence. However, reducing secondary flows did not decrease the overall loss in the stator. The concept might still be useful for eliminating massive separations caused by small secondary flows.

\section{REFERENCES}

Anderson, B. H., and Gibb, J., 1998, "Vortex Generator Installation Studies on Steady-State and Dynamic Distortion," J. Aircraft, Vol. 35, No. 4, pp. 513-520.

Anderson, B. H., Miller, D. N., Truax, P. P., and Yeagle, P. J., 1999, “A Study on MEMS Flow Control for the Management of Engine Face Distortion in Compact Inlet Systems," ASME/JSME Paper ZFEDSM99-6920.

Bender, E. E., Anderson, B. H., and Yagle, P. J., 1999, "Vortex Generator Modeling for Navier-Stokes Codes,” ASME Paper FEDSM99-6919.

Bons, J. P., Sondergaard, R., and Rivir, R. B., 2000, “Turbine Separation Control Using Pulsed Vortex Generator Jets," ASME Paper 200GT-0262.

Chima, R. V., 1987, "Explicit Multigrid Algorithm for Quasi-ThreeDimensional Viscous Flows in Turbomachinery," J. Propulsion and Power, Vol. 3, No. 5, pp. 397-405.
Chima, R. V., 1992, "Viscous Three-Dimensional Calculations of Transonic Fan Performance," in CFD Techniques for Propulsion Applications, AGARD Conference Proceedings No. CP-510, AGARD, Neuilly-Sur-Seine, France, pp 21-1 to 21-19. Also NASA TM-103800.

Chima, R. V., 1995, “A k- $\omega$ Turbulence Model for Quasi-Three-Dimensional Turbomachinery Flows," AIAA Paper 96-0248. Also NASA TM-107051.

Chima, R. V., 1996, "Calculation of Tip Clearance Effects in a Transonic Compressor Rotor,” ASME Paper 96-GT-114. Also NASA TM107216.

DeCook, S. J., King, P. I., and Elrod, W. C., 1993, "Wake Mixing and Performance of a Compressor Cascade with Crenulated Trailing Edges," J. Propulsion and Power, Vol. 9, pp 293-300.

Dixon S. L., 1975, Fluid Mechanics, Thermodynamics of Turbomachinery, Pergamon Press, N.Y., pp 52-58.

Gammerdinger, P. M., 1995, "The Effects of Low-Profile Vortex Generators on Flow in a Transonic Fan-Blade Cascade," M.S. Thesis, Naval Postgraduate School, Monterey, CA.

Kuethe, A. M., 1972, "Effect of Streamwise Vortices on Wake Properties Associated with Sound Generation," J. Aircraft, Vol. 9, No. 10, pp 8-12.

Larosiliere, L. M., Wood, J. R., and Hathaway, M. J., 2001, “Aerodynamic Design Study of an Advanced Multistage Axial Compressor, Part I: Level of Technical Advancement," NASA TM in preparation.

Law, C. H., Wennerstrom, A. J., and Buzzell, W. A., 1976, "The Use of Vortex Generators as Inexpensive Compressor Casing Treatment," SAE Paper 760925.

Liou, T.-M., Chen, C.-C., and Tsai, T.-W., 1999, "Heat Transfer and Fluid Flow in a Square Duct With 12 Different Shaped Vortex Generators," ASME Paper 99-GT-255.

Marble, F. E., “Three-Dimensional Flow in Turbomachines," in High Speed Aerodynamics and Jet Propulsion, Vol. X, Aerodynamics of Turbines and Compressors, Hawthorne, W. R., ed., Princeton University Press, Princeton, NJ, 1964, pp. 83-165.

McCormick, D. C., 1993, "Shock/Boundary Layer Interaction Control With Vortex Generators and Passive Control," AIAA J., Vol. 93, No. 1, pp 91-96.

Medd, A. J., Dang, T. Q., Larosiliere, L. M., Wood, J. R., and Hathaway, M. J., 2001, "Aerodynamic Design Study of an Advanced Multistage Axial Compressor, Part I: 3D Blading Development," NASA TM in preparation.

Pearcey, H. H., 1961, "Shock-induced Separation and its Prevention," in Boundary Layer and Flow Control, Its Principles and Application, Vol. 2, edited by G. V. Lachmann, Pergamon Press.

Roskam, J. and Lan, C.-T. E., 1997, "Airplane Aerodynamics and Performance," DARcorporation pub, Kansas, pp 117-118.

Wendt, B. J., and Dudek, J. C., 1998, "Development of Vortex Generator Use for a Transitioning High-Speed Inlet," J. Aircraft, Vol. 35, No. 4, pp 536-543.

Wennerstrom, A., 1987, "Some Experiments With a Supersonic Axial Compressor Rotor,” J. Turbomachinery, Vol. 109, pp 388-393. 
Public reporting burden for this collection of information is estimated to average 1 hour per response, including the time for reviewing instructions, searching existing data sources, gathering and maintaining the data needed, and completing and reviewing the collection of information. Send comments regarding this burden estimate or any other aspect of this collection of information, including suggestions for reducing this burden, to Washington Headquarters Services, Directorate for Information Operations and Reports, 1215 Jefferson Davis Highway, Suite 1204, Arlington, VA 22202-4302, and to the Office of Management and Budget, Paperwork Reduction Project (0704-0188), Washington, DC 20503.

\begin{tabular}{|l|r|r|}
\hline 1. AGENCY USE ONLY (Leave blank) & $\begin{array}{c}\text { 2. REPORT DATE } \\
\text { April } 2002\end{array}$ & $\begin{array}{r}\text { 3. REPORT TYPE AND DATES COVERED } \\
\text { Technical Memorandum }\end{array}$ \\
\hline
\end{tabular}

4. TITLE AND SUBTITLE

5. FUNDING NUMBERS

Computational Modeling of Vortex Generators for Turbomachinery

6. AUTHOR(S)

WU-714-03-50-00

R.V. Chima

7. PERFORMING ORGANIZATION NAME(S) AND ADDRESS(ES)

National Aeronautics and Space Administration

John H. Glenn Research Center at Lewis Field

Cleveland, Ohio 44135-3191

8. PERFORMING ORGANIZATION

REPORT NUMBER

E-13326

9. SPONSORING/MONITORING AGENCY NAME(S) AND ADDRESS(ES)

National Aeronautics and Space Administration

Washington, DC 20546-0001

10. SPONSORING/MONITORING

AGENCY REPORT NUMBER

NASA TM-2002-211551

GT-2002-30677

\section{SUPPLEMENTARY NOTES}

Prepared for the Turbo Expo 2002 cosponsored by the American Society of Mechanical Engineers and the International Gas Turbine Institute, Amsterdam, The Netherlands, June 3-6, 2002. Responsible person, R.V. Chima, organization code 5810, 216-433-5919.

12a. DISTRIBUTION/AVAILABILITY STATEMENT

12b. DISTRIBUTION CODE

Unclassified - Unlimited

Subject Category: 07

Distribution: Nonstandard

Available electronically at http://gltrs.grc.nasa.gov/GLTRS

This publication is available from the NASA Center for AeroSpace Information, 301-621-0390.

13. ABSTRACT (Maximum 200 words)

In this work computational models were developed and used to investigate applications of vortex generators (VGs) to turbomachinery. The work was aimed at increasing the efficiency of compressor components designed for the NASA Ultra Efficient Engine Technology (UEET) program. Initial calculations were used to investigate the physical behavior of VGs. A parametric study of the effects of VG height was done using 3-D calculations of isolated VGs. A body force model was developed to simulate the effects of VGs without requiring complicated grids. The model was calibrated using 2-D calculations of the VG vanes and was validated using the 3-D results. Then three applications of VGs to a compressor rotor and stator were investigated: 1) The results of the 3-D calculations were used to simulate the use of small casing VGs used to generate rotor preswirl or counterswirl. Computed performance maps were used to evaluate the effects of VGs. 2) The body force model was used to simulate large part-span splitters on the casing ahead of the stator. Computed loss buckets showed the effects of the VGs. 3) The body force model was also used to investigate the use of tiny VGs on the stator suction surface for controlling secondary flows. Near-surface particle traces and exit loss profiles were used to evaluate the effects of the VGs.

14. SUBJECT TERMS

Computational fluid dynamics; Turbomachinery; Vortex generators

PAGES

\begin{tabular}{|c|c|c|}
\hline $\begin{array}{c}\text { 17. SECURITY CLASSIFICATION } \\
\text { OF REPORT } \\
\text { Unclassified }\end{array}$ & $\begin{array}{c}\text { 18. SECURITY CLASSIFICATION } \\
\text { OF THIS PAGE } \\
\text { Unclassified }\end{array}$ & $\begin{array}{c}\text { 19. SECURITY CLASSIFICATION } \\
\text { OF ABSTRACT } \\
\text { Unclassified }\end{array}$ \\
\hline
\end{tabular}

NSN 7540-01-280-5500

Standard Form 298 (Rev. 2-89)

Prescribed by ANSI Std. Z39-18 298-102 